
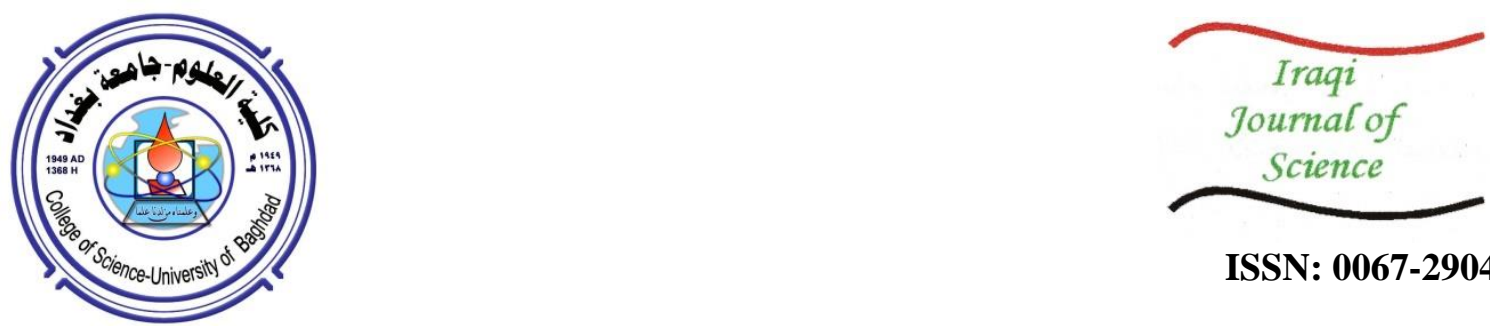

ISSN: 0067-2904

\title{
Optimum Selection of Wind Turbines Using Normalized Power and Capacity Factor Curves
}

\author{
Firas A. Hadi ${ }^{* 1}$, Zaid F. Makki ${ }^{2}$, Rafa A. Al-Baldawi ${ }^{3}$ \\ ${ }^{1}$ Department Environment Science, College of Energy and Environmental Sciences, Al-karkh University of \\ Science, Baghdad, Iraq \\ ${ }^{2}$ Alnahrain Centre for Strategic Studies, Baghdad, Iraq \\ ${ }^{3}$ College of Energy and Environmental Sciences, Al-karkh University of Science, Baghdad, Iraq
}

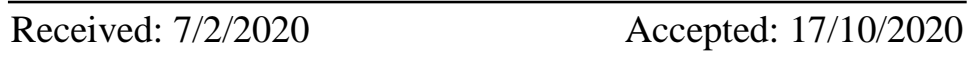

\begin{abstract}
The main objective of this paper is present a novel method to choice a certain wind turbine for a specific site by using normalized power and capacity factor curves. The site matching is based on identifying the optimum turbine rotation speed parameters from turbine performance index (TPI) curve, which is obtained from the higher values of normalized power and capacity factor curves. Wind Turbine Performance Index a new ranking parameter, is defined to optimally match turbines to wind site. The relations (plots) of normalized power, capacity factor, and turbine performance index versus normalized rated wind speed are drawn for a known value of Weibull shape parameter of a site, thus a superior method is used for Weibull parameters estimation which is called Equivalent Energy Method (EEM).
\end{abstract}

Keywords: Capacity factor, Normalized power, Turbine performance index.

\section{الاختيار الأمثل لتوربينات الرباح باستخدام منحنى القدرة المعياري وعامل السعة

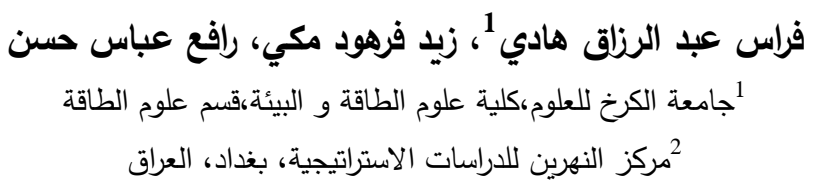

الخلاصة

الهدف الرئيسي من هذا البحث هو تقديم طريقة جديدة لاختيار توربين رياح أمثل لموقع معين باستخدام

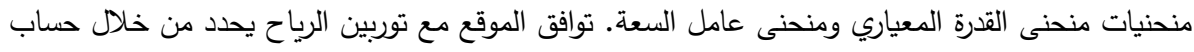

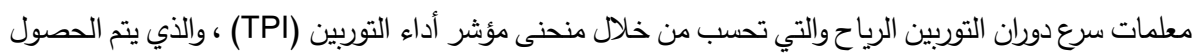

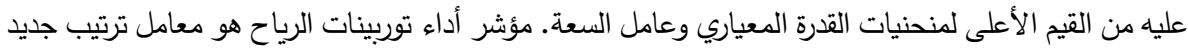

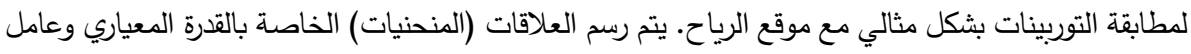

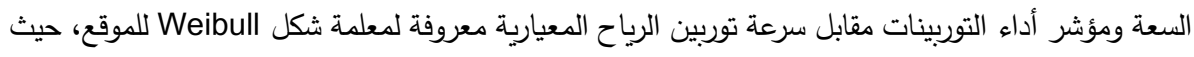

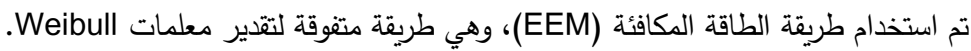




\section{Introduction}

The process of generating electric power by wind turbine systems at a particular location depending on many factors, the most important of these factors is the wind speed at that location and most notably the wind turbine speed characteristics themselves; namely, rated speed $\left(v_{\mathrm{r}}\right)$, cut-in speed $\left(v_{\mathrm{c}}\right)$ and furling or cut-out speed $\left(v_{\mathrm{f}}\right)$ including wind turbine hub height [1]. Table 1 gives a description of some of the turbines currently available, which have also been used for the purpose of determining the most suitable turbine for the study site.

Table 1- Specification of Some Available Wind Turbine Generator System

\begin{tabular}{|l|l|l|l|l|l|l|l|}
\hline Make & $\begin{array}{l}\text { Rating } \\
\text { Power } \\
{[\mathbf{k W}]}\end{array}$ & $\begin{array}{l}\text { Operating Data } \\
\boldsymbol{v}_{\mathbf{c}}\end{array}$ & $\begin{array}{l}\boldsymbol{v}_{\mathbf{r}} \\
\mathbf{m} / \mathbf{s}\end{array}$ & $\begin{array}{l}\mathbf{v}_{\mathbf{f}} \\
\mathbf{m} / \mathbf{s}\end{array}$ & No. Blades. & $\begin{array}{l}\text { Rotor } \\
\text { diameter } \\
{[\mathbf{m}]}\end{array}$ & $\begin{array}{l}\text { Rated } \\
\text { Power [kW] }\end{array}$ \\
\hline Fortis & 5 & 3 & 21 & 25 & 3 & 5 & 5 \\
\hline Aircon 10S & 10 & 3.5 & 11 & 25 & 3 & 7.1 & 9.8 \\
\hline C\&F energy & 20 & 1.5 & 9 & 15 & 3 & 13.1 & 20 \\
\hline G3120 & 35 & 3.5 & 11 & 25 & 3 & 19.2 & 35 \\
\hline Orenda & 49 & 4 & 10 & 25 & 3 & 18.9 & 49 \\
\hline Deimos & 60 & 3 & 9 & 25 & 3 & 21.5 & 60 \\
\hline Electriawind & 150 & 2.5 & 9 & 25 & 3 & 38 & 100 \\
\hline Micon & 200 & 4 & 14 & 25 & 3 & 30 & 200 \\
\hline Endurance & 225 & 4 & 15 & 25 & 3 & 29.1 & 225 \\
\hline Enercon & 800 & 3 & 12 & 34 & 3 & 48 & 800 \\
\hline Vestas & 850 & 4 & 14 & 25 & 3 & 52 & 850 \\
\hline
\end{tabular}

The most important characteristic speed for wind turbine design is the rated speed [1]. If a low rated speed is chosen to take advantage of the low wind speed within an area, a lot of energy will be lost at the higher wind speed. Conversely, if the wind turbine rated speed is selected too high, the turbine rarely operates at its estimated capacity and will also lose a lot of energy at low wind speed. This means that the rated speed must be determined so that the turbine produces higher energy. Usually $v_{\mathrm{c}}$ is chosen approximately as half $v_{\mathrm{r}}$, While $v_{\mathrm{f}}$ estimated as twice of $v_{\mathrm{r}}$ value [1]. The relation between turbine wind speeds as will be seen in this work are $v_{\mathrm{c}}=0.259 v_{\mathrm{r}}$ and $v_{\mathrm{f}}=1.95 v_{\mathrm{r}}$. Here, it is important to define an important factor which is called Capacity factor $\left(\mathrm{C}_{\mathrm{f}}\right)$. This factor represents the ratio of the output expected energy from wind turbine over a period of time to the estimated power of the wind turbine generator. The TPI curve could be found by capacity factor and normalized curves and is plotted on the same axis of the normalized rated speed [2]. From the above, it can be said that it is advisable to choose the optimal wind turbine for a particular location in order to obtain the highest wind potential energy. These important aspects raise concerns regarding suitability, taking into account the energy potential of a particular site and selecting the appropriate wind turbines for a specific wind profile [3]. In this paper the Wind Turbine Performance Index (TPI) concept is introduced, there is an ideal TPI curve for each study site from which an optimized wind turbine speeds that will match the site optimally could be found.

\section{Area of Study}

The study site is located in the holy area of Karbala - Republic of Iraq and specifically Al-Razzaza Lake. This Lake is located $15 \mathrm{~km}$ north west of Karbala. It is part of a wide valley that includes al-Tharthar, Al-Habbaniya, Al-Razzaza and Bahr Najaf (Najaf Sea). The lake is supplied by eight sources, including the River Euphrates; Lake Habaniya, east of Ramadi; Rashidiya, north of Karbala; groundwater springs in Ayn al-Tamr, 80km west of Karbala; rainwater and seasonal flows. Located to the west of the Iraqi holy city of Karbala with coordinates 323736 N, 435342E, as shown in Figure-1. This location has been chosen based on the global wind distribution map produced by Global Wind Atlas. Through this map, there is an abundance of high wind speeds in the western region of Iraq, where the average speed through the year ranges between $5.00-6.00 \mathrm{~m} / \mathrm{s}$ at $50 \mathrm{~m}$ height, and high speeds are concentrated almost in two areas, 
Al-Razzaza and Tharthar lakes. In this research, Al-Razzaza lake was chosen to find suitable offshore wind generators for this site being one of the promising areas in Iraq (marginal class) [4].

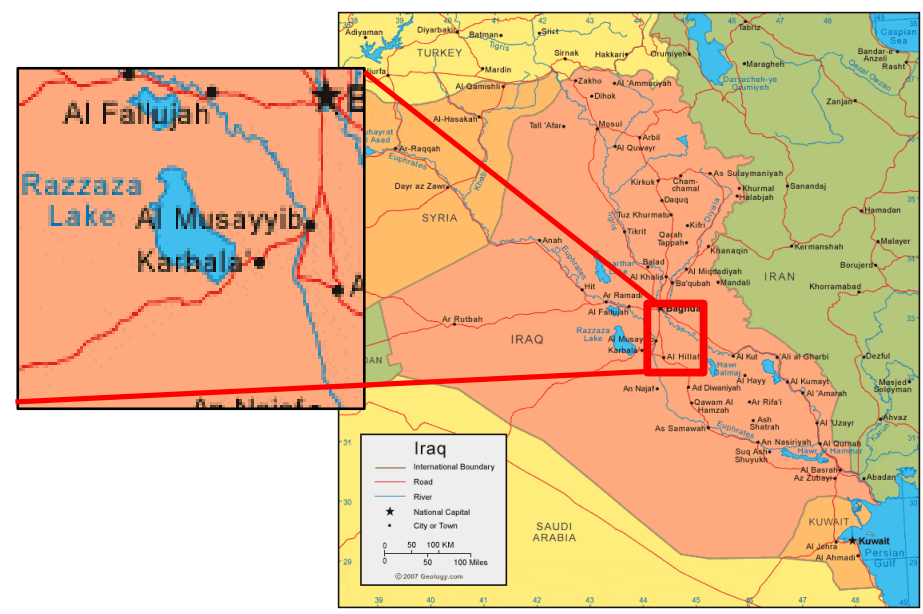

Figure 1- area of study in Iraq country

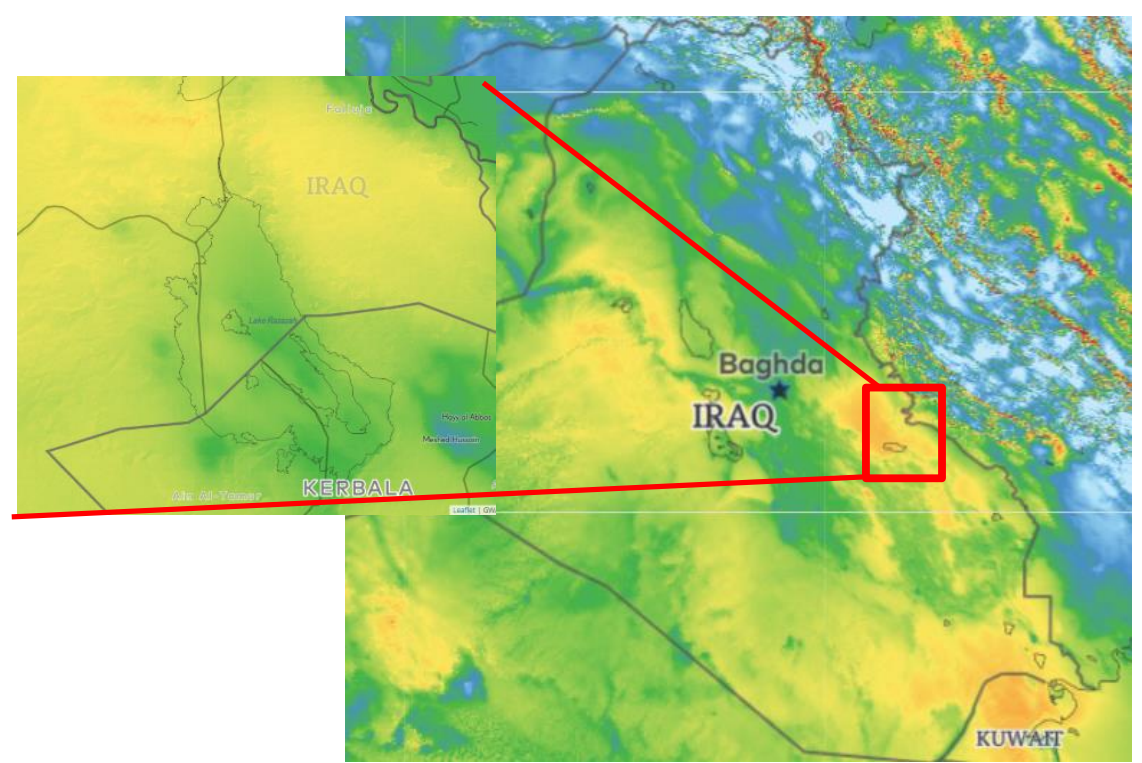

Figure 2- wind speed distrubution in Iraq country at 50m height[4]

\section{Data Specification work}

MERRA data downloaded from Windnavigator using Windographer Data Downloader. This data is registered from NASA Global Modeling and Assimilation Office which provided from AWS Truepower, LLC, a UL Company, and contains hourly wind speed and wind direction for the period between 1979-2016. All readings are measured at 50m height from sea-surface and will be downloaded after giving the proceedings coordinates (Lat., Long.) [2].

\section{Mathematical Formulation}

Before entering into the theoretical concepts of the work, basic concepts about the mathematical structure of research must be taken, as follows

\subsection{Weibull Distribution of Wind Speed}

The wind speed Weibull distribution function can be given by wind speed frequency curve (probability density function) [1]:

$$
f(v)=\frac{k}{c}\left(\frac{v}{c}\right)^{k-1} \exp \left[-\left(\frac{v}{c}\right)^{k}\right]
$$

Where, the cumulative distribution function for wind speed (v) is given by [1]: 


$$
F(v)=1-\exp \left[-(v / c)^{k}\right]
$$

Where, $\mathrm{c}$ represents the scale factor (has unit of speed) and $\mathrm{k}$ represents the shape factor (without dimension). A new method for estimating Weibull parameters is called the Equivalent Energy Method (EEM) which examined by [5]. This method is based on the energy content of the distribution and has been developed to improve the accuracy of the parameters. This new determines Weibull parameters that best fit the measured wind speed distribution and is equal to the wind speed cubic. According to the Weibull distribution, the probability of a wind speed greater than or equal to a specified value, $v$, is defined by [5]:

$$
P(v)=\exp \left[-(v / c)^{k}\right]
$$

Now, it is possible to represents the probability of wind speeds which is lower than $\mathrm{v}$ and greater than or equal to $\mathrm{v}-1$ and (i.e. $\mathrm{v}-1 \leq \mathrm{v}<\mathrm{v}$ ) is:

$$
\begin{gathered}
P(v)=P(v-1)-P(v) \\
P(v)=\exp \left[-\left(\frac{v-1}{c}\right)^{k}\right]-\exp \left[-\left(\frac{v}{c}\right)^{k}\right]
\end{gathered}
$$

Statistically, a stochastic variable $\mathrm{Pv}$ could be represented by the probability function $\mathrm{P} v$ added to a stochastic term $\varepsilon$, such as:

$$
P_{v}=P(v)+\varepsilon=\left(\exp \left[-\left(\frac{v-1}{c}\right)^{k}\right]-\exp \left[-\left(\frac{v}{c}\right)^{k}\right]\right)+\varepsilon
$$

Using the condition of energy content equivalence between the observed wind speeds and the Weibull distribution, the scale factor, $\mathrm{c}$, can be written from the mean cube expression as:

$$
c=\left(\frac{(v)^{3}}{\Gamma\left(1+\frac{3}{k}\right)}\right)^{1 / 3}
$$

Eq.7 in Eq.6 yields:

$$
P_{v}=\exp \left[-\left(\frac{(v-1)\left(\Gamma\left(1+\frac{3}{k}\right)^{\frac{1}{3}}\right)}{\bar{v}}\right)^{k}\right]-\exp \left[\left(\frac{v\left(\Gamma\left(1+\frac{3}{k}\right)^{\frac{1}{3}}\right)}{\bar{v}}\right)^{k}\right]+\varepsilon
$$

Where $\mathrm{v}^{-}$represents the mean wind speed. The Weibull shape factor, $\mathrm{k}$, can be estimated by applying the least squares technique to the following expression [6]:

$$
\begin{aligned}
\sum_{i}^{n} & =1\left[P_{v_{i}}-\exp -\left(\frac{\left(v_{i}-1\right)\left(\Gamma\left(1+\frac{3}{k}\right)\right)^{\frac{1}{3}}}{\bar{v}}\right)^{k}+\exp \right. \\
& \left.-\left(\frac{v_{i}\left(\Gamma\left(1+\frac{3}{k}\right)\right)^{\frac{1}{3}}}{\bar{v}}\right)^{k}\right]^{2}=\sum_{i=1}^{n}\left(\varepsilon_{i}\right)^{2}
\end{aligned}
$$

Where $P_{v_{i}}$ is the probability of having wind speeds for $\mathrm{i}^{\text {th }}$ bin, $\mathrm{n}=$ is the number of bins of the wind speed histogram, $v_{\mathrm{i}}=$ is the highest wind speed value of the $\mathrm{i}^{\text {th }}$ bin, $v_{m}^{3}=$ the mean cube (observed).

After $\mathrm{k}$ is compute, the scale factor is calculated from Eq.7.

\subsection{Capacity Factor}

The capacity factor can be obtained from the following equation [7]:

$$
C_{f}=\frac{\exp \left[-\left(v_{c} / c\right)^{k}\right]-\exp \left[-\left(v_{r} / c\right)^{k}\right]}{\left(v_{r} / c\right)^{k}-\left(v_{c} / c\right)^{k}}-\exp \left[-\left(v_{f} / c\right)^{k}\right]
$$

Where, $C_{f}$ is the capacity factor, while $v_{\mathrm{c}}, v_{\mathrm{r}}$, and $v_{\mathrm{f}}$ are defined before, $\left(v_{\mathrm{r}} / \mathrm{c}\right)$ is normalized rated speed. It is clear that the capacity factor is a function of the main turbine parameters $v_{\mathrm{c}}, v_{\mathrm{r}}$, and $v_{\mathrm{f}}$ also the site parameters $c$ and $k$.

\subsection{Normalized Power}

The resulting power of the wind turbine generator can be written as follows [1]: 


$$
P_{e}(v)=0.5 C_{p} \eta_{m} \eta_{e} \rho A v^{3}
$$

Where $\eta_{m}, \eta_{e}=$ the efficiencies of the mechanical transmission system and the electrical generation system,

$\rho=$ air density, $\mathrm{A}=$ turbine sweep area, $C p=$ power coefficient of the turbine. The models of pitch controlled blades are based on three characteristic speeds $v_{\mathrm{c}}, \mathrm{v}_{\mathrm{r}}, v_{\mathrm{f}}$ and on the rated power $P_{\mathrm{r}}$, while the rising curve between $v_{\mathrm{c}}$ and $v_{\mathrm{r}}$ can be well approximated with a quadratic model. Therefore, $P_{\mathrm{e}}(v)$ can be written as follows [1]:

$$
P_{e}(v)=P_{r}\left\{\begin{array}{cc}
0 & v<v_{c} \text { or } v>v_{f} \\
\frac{v^{2}-v_{c}^{2}}{v_{r}^{2}-v_{c}^{2}} & v_{c} \leq v \leq v_{f} \\
1 & v_{r} \leq v \leq v_{f}
\end{array}\right\}
$$

Where $P_{r}(v)=0.5 C_{p r} \eta_{m r} \eta_{e r} \rho A v_{r}^{3}, C_{p r}=$ the coefficient of performance at rated wind speed vr, $\eta_{m r}=$ the mechanical interface efficiency at rated power, $\eta_{e r}=$ the generator efficiency at rated power. By integrating the multiplication of Eq. 12 and Eq. 1, the average electrical power produced by a wind turbine can be represented by:

$$
P_{e, a v}=\int_{0}^{\infty} P_{e}(v) f(v) d v
$$

Where $f(v)$ is a probability density function of wind speeds, using the method of Pe,

$$
\begin{gathered}
P_{e, a v}=P_{r}\left\{\int_{v_{c}}^{v_{r}}\left[\frac{v^{2}-v_{c}^{2}}{v_{r}^{2}-v_{c}^{2}}\right] \frac{K}{c}\left(\frac{v}{c}\right)^{K-1} \exp \left[-\left(\frac{v}{c}\right)^{K}\right] d v\right. \\
\left.+\int_{v_{r}}^{v_{f}} \frac{K}{c}\left(\frac{v}{c}\right)^{K-1} \exp \left[-\left(\frac{v}{c}\right)^{K}\right] d v\right\}
\end{gathered}
$$

Normalizing the average electric power $\left(P_{e, a v}\right)$ equation by rated output power is defined as:

$$
P_{N}=\frac{P_{e, a v}}{0.5 C_{p r} \eta_{m r} \eta_{e r} \rho A c^{3}}=c_{f}\left(\frac{v_{r}}{c}\right)^{3}
$$

Where $P_{\mathrm{N}}$ the normalized power.

\subsection{Turbine Performance Index (TPI)}

Obviously, the increase in normalized power (with a corresponding value $v_{\mathrm{r}} / \mathrm{c}$ ) is associated with a decrease in the power factor and vice versa. Therefore, a value of $\left(v_{\mathrm{r}} / \mathrm{c}\right)$ is expected, at which the product of the variables $P_{N}$ and $C_{f}$ for $\left(v_{\mathrm{r}} / \mathrm{c}\right)$ will obtain maximum individual values of $P_{N}$ and $C_{f}$.

This value $\left(v_{\mathrm{r}} / \mathrm{c}\right)$ that corresponds to $\left(P_{N}^{*} C_{f}\right)$ max is between the values of $\left(v_{\mathrm{r}} / \mathrm{c}\right)$ for $P_{N, \text { max }}$, and $C_{f, \max }$. This means that it is possible to choose $\left(v_{\mathrm{r}} / \mathrm{c}\right)$ for a site at which the total energy product is closer to maximum at a higher capacity factor. This means that it is possible to choose $\left(v_{\mathrm{r}} / \mathrm{c}\right)$ for a location where the total power output is closer to the maximum in a higher power factor. This value $\left(v_{\mathrm{r}} / \mathrm{c}\right)$ and the corresponding optimal cutting and reduction speeds are evaluated using $v_{c}=\mathrm{x}_{1} v_{r}$ and $v_{f}=\mathrm{x}_{2} v_{r}$. where $\mathrm{x}_{1}$ and $x_{2}$ are two practical values. Thus, on the basis of the above discussion, the TPI is defined as [8]:

$$
T P I=\frac{P_{N} \times C_{f}}{P_{N, \max } \times C_{f, \max }}
$$

The TPI is a function of the usual rated speed, and is drawn with normalized power and power factor curves. Optimization $\left(v_{\mathrm{r}} / \mathrm{c}\right)$ corresponds to the maximum TPI. Apply natural strength, capacity factor and turbine performance index curves to determine the optimal wind turbine parameters for the site.

\section{Results and Discussions}

Wind roses are constructed using a composite of data wind speed which measured at $50 \mathrm{~m}$ height from earth sea level. Three types of information can be presented in Figure- 1. (1) The percentage of time from which it can be receive the wind from a particular direction. This can show the direction from which it can be get most of the wind. As for the study area, it is clear from the figure that the main 
prevailing wind sector is 330 , followed by sector 300 and both sectors are located in the northwest direction. In addition, approximately $5 \%, 15 \%$ and $5 \%$ of total time the wind blows at $8-12 \mathrm{~m} / \mathrm{s}, 4-8 \mathrm{~m} / \mathrm{s}$, and $0-4 \mathrm{~m} / \mathrm{s}$, respectively, from the sector 330. (2) The multiplication between the percentages of time from which it can be receive wind from a particular direction and the average wind speed at this direction. This tells us the average strength of the wind spectra at sector 300 is more than the others (which corresponds to the direction North-West). (3) The product of time percentage and cube of the wind velocity. This helps us in identifying the energy available from different directions, and the highest value lie at sector 330 .

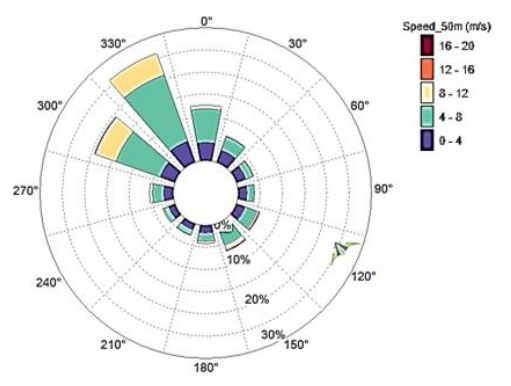

Frequency of speed vs. direction at $50 \mathrm{~m}$ height,

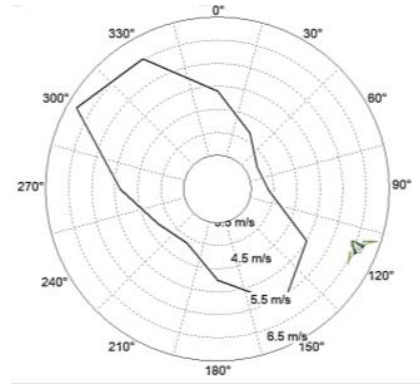

Mean of speed vs. direction at $50 \mathrm{~m}$ height

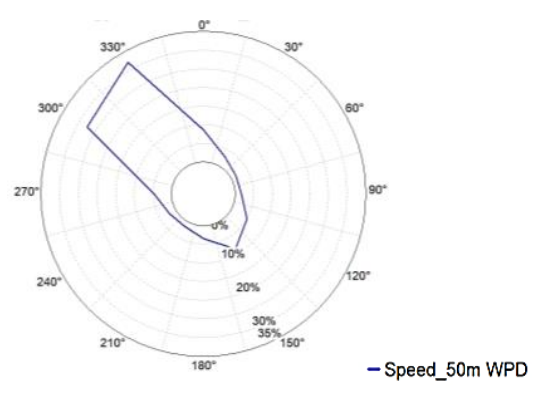

Proportion of total wind energy vs. direction at $50 \mathrm{~m}$ height

Figure 1- Wind Roses as frequency, speed, and energy (1/1/1979-29/2/2016)

Figure- 2 shows monthly based wind rose for 50 meter height, it helps in understanding the variability in the wind direction in every month. Simply, it could infer that the main prevailing wind direction in study area is North-West, while the dominant wind directions in all months were arranged between North-West 300 and 330 sectors. In more details, winds blow from 300 and 330 sectors have occurrences between $10-40 \%$, thus sector 330 is the most dominant one, and it reaches its maximum value at approximately $40 \%$ from total records in Jun.
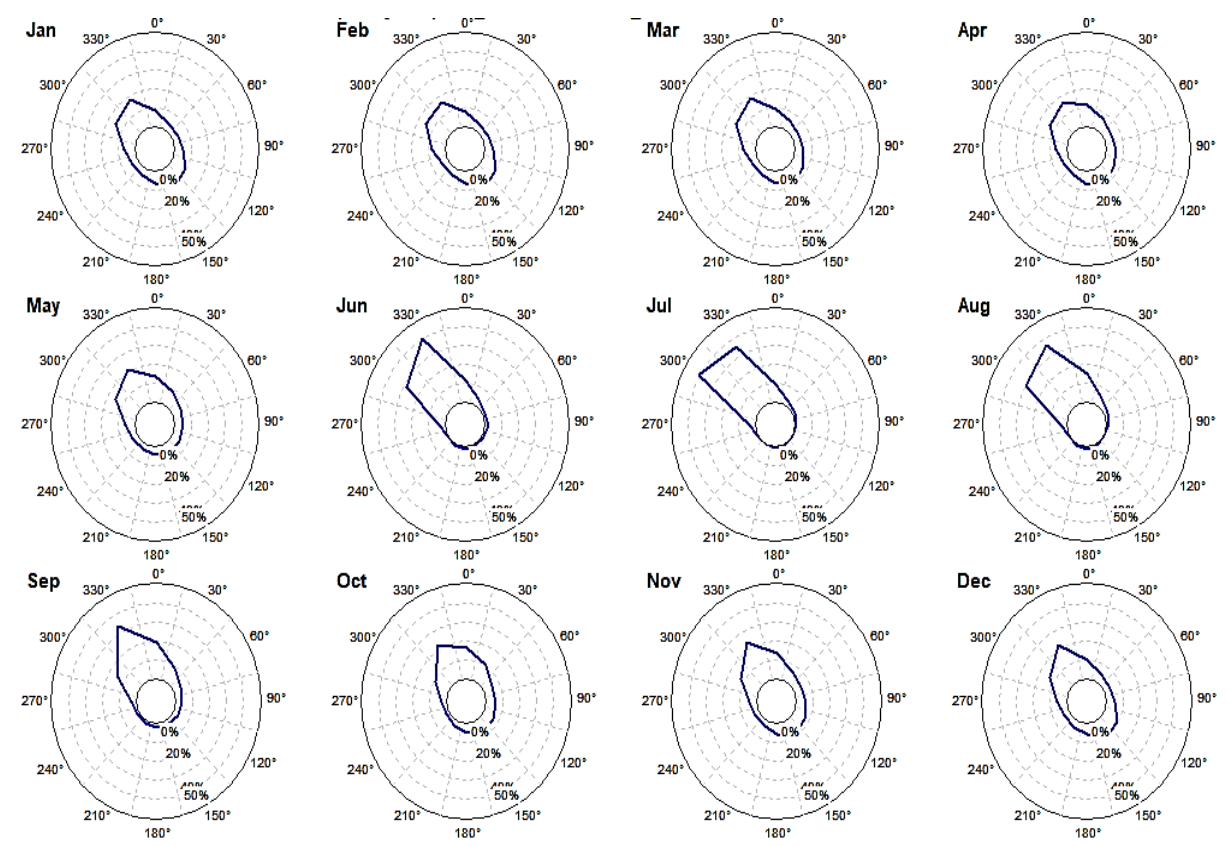

Figure 2- Monthly frequency of speed at 50m height vs. direction, 1/1/1979-2/29/2016

Figure-3 shows the rate of change in average wind speed during the months of the year. From this figures, it can be infer generally, that the mean wind speeds are high at first morning hours of the day ( 0 $\mathrm{am}$ ), after that the mean wind speed will begin to be stable or with little change till $6 \mathrm{pm}$, where the mean wind speed will begin to increase again. 

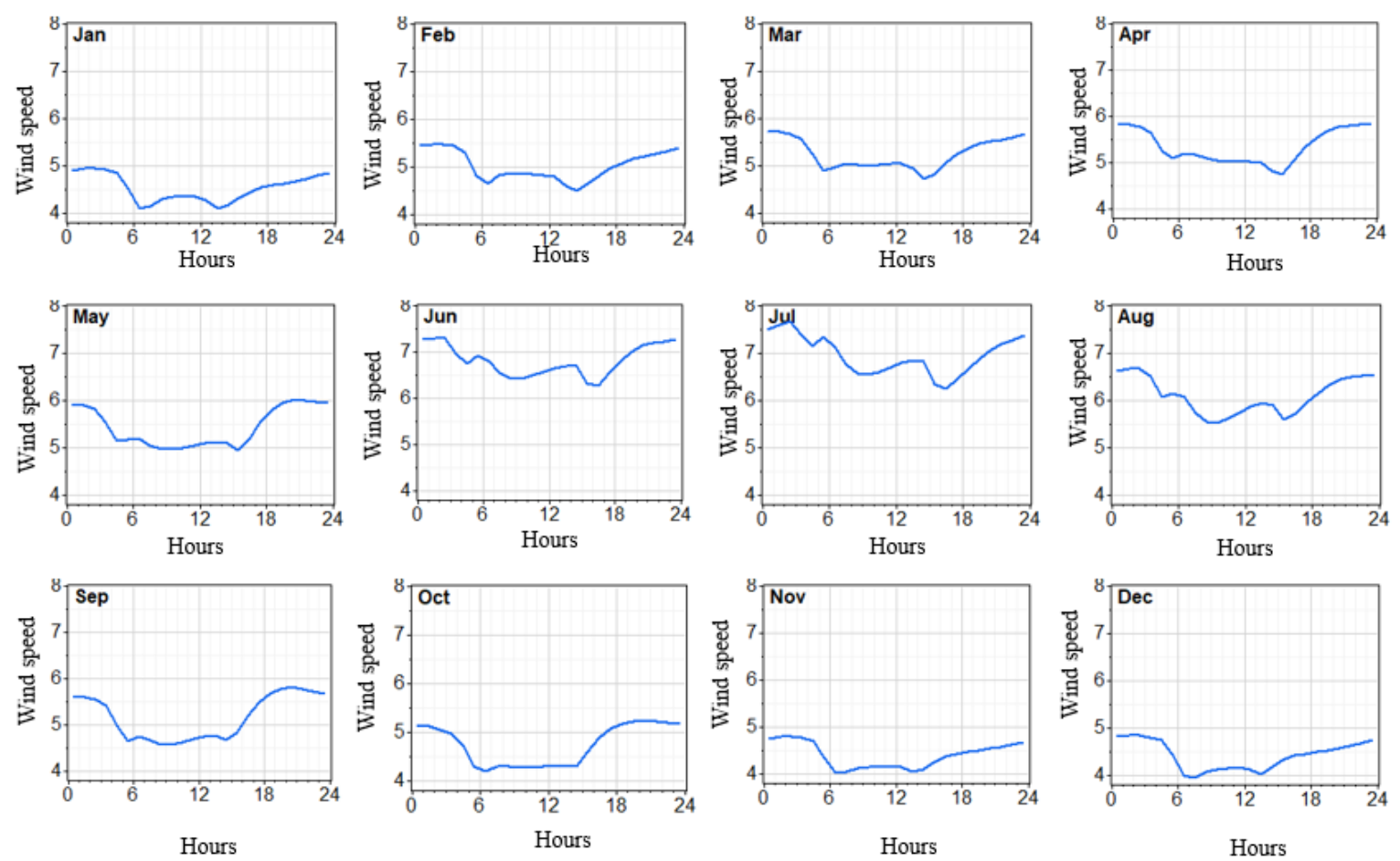

Figure 3- Hourly wind speed variation for each month

A computer program has been built by researchers to determine the optimum site matching of wind turbines. Al-Razzaza site in Iraq has been used in this study for mean wind speed $5.4[\mathrm{~m} / \mathrm{sec}]$ at height $50 \mathrm{~m}$. Capacity factor and normalized power are computed for different values of $\mathrm{k}$ and $\left(v_{\mathrm{r}} / \mathrm{c}\right)$. Figure- 4 shows two sets of general normalized curves drawn on common $\mathrm{x}$-axis. One set of curves represents the capacity factors and the second set represents normalized power. For both curves, $\mathrm{k}$ is varied from 1 to 2.6 in steps of 0.4 and $\left(v_{\mathrm{r}} / \mathrm{c}\right)$ is varied from $0.0-3.94$ in steps of 0.3 .
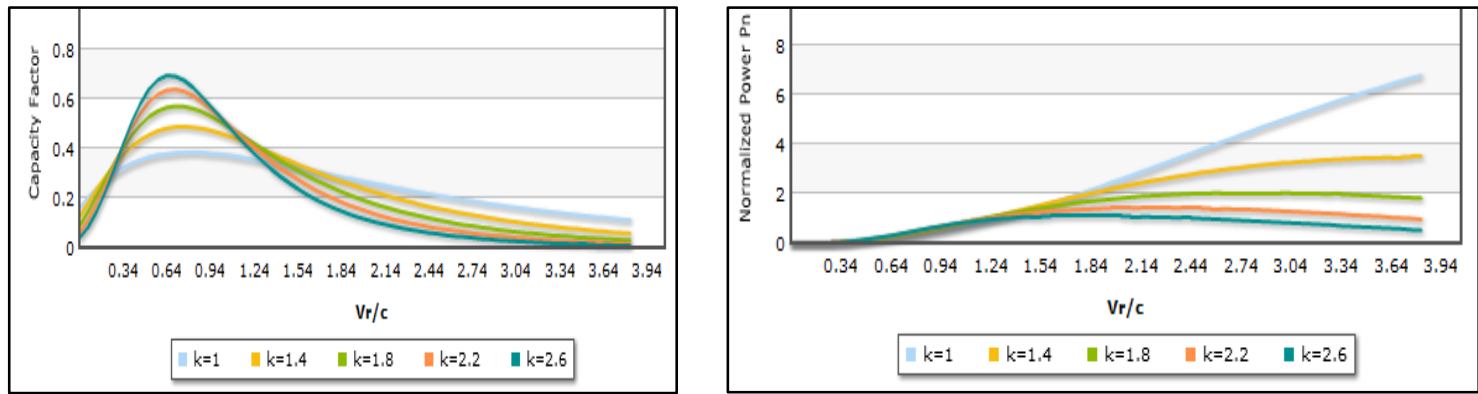

Figure 4- Normalized power and capacity factor curves at height $10 \mathrm{~m}$

A set of values of $k$ and $\left(v_{\mathrm{r}} / \mathrm{c}\right)$ are chosen to include the different sites and turbine specifications. By replacing the relationship $v_{\mathrm{c}}=\mathrm{x}_{1} v_{\mathrm{r}}$ and $v_{\mathrm{f}}=\mathrm{x}_{2} v_{\mathrm{r}}$ in Eq. 10, the normalized power can be fully expressed in terms of rated wind speed $\left(\mathrm{v}_{\mathrm{r}} / \mathrm{c}\right)$ and Weibull shape parameter $(k)$. To reach both $\mathrm{x}_{1}$ and $\mathrm{x}_{2}$ values, a survey was conducted by many researchers, such that more than 120 types of wind turbines with different rated power and turbine speed parameters was used. From this survey, it was observed that the value of $\mathrm{x}_{1}$ ranging from 0.252 to 0.266 with 0.259 average such that the standard deviation error is 0.0374 with $95 \%$ confidence. The value of $x_{2}$ ranging from 1.906 to 1.998 with average value 1.95 such that the standard deviation error is 0.258 with $95 \%$ confidence. In this paper, the average values of $\mathrm{x}_{1}$ and $\mathrm{x}_{2}$ were used, thus, the wind turbine speed parameters relationships can be expressed as follows:

$$
\begin{aligned}
& v_{\mathrm{c}}=0.259 v_{\mathrm{R}} \\
& v_{\mathrm{f}}=1.950 v_{\mathrm{R}}
\end{aligned}
$$


Figure-5 shows the following: When the capacity factor $C_{f}$ reaches its highest value, the normalized power $P_{N}$ value is very low, and vice versa. When the normalized power reaches its highest value, the capacity factor have a small value.

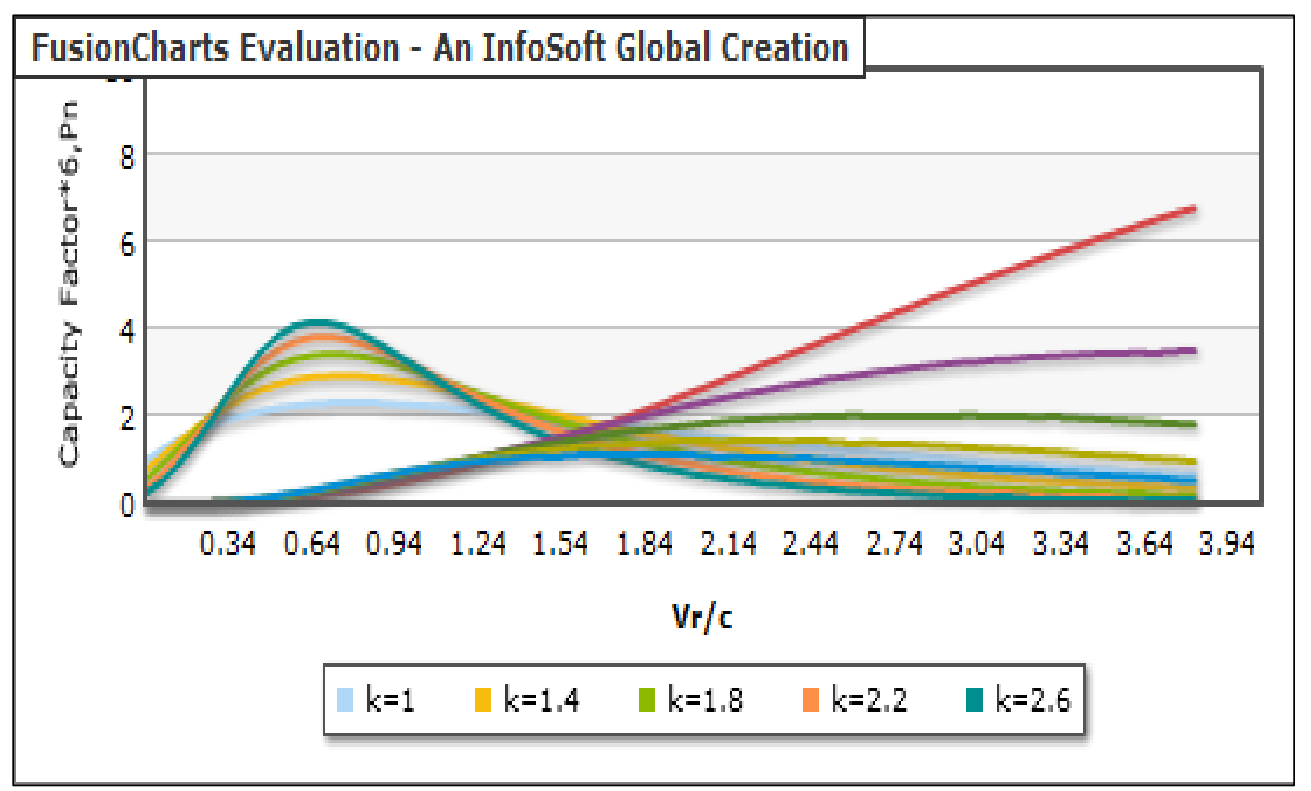

Figure 5- Normalized power and capacity factor curve.

The high rated speed values are accompanied by a decrease in capacity factor which in turn means that the turbine will work in relatively less amount of time. This requires to obtain $v_{r} / \mathrm{c}$ which is corresponding to maximum value of TPI, then by knowing Weibull scale factor (c) it is possible to calculate the rated speed of wind turbine $\left(v_{\mathrm{r}}\right)$. Finally, by using equations (17) and (18) it is possible to calculate the other wind turbine velocities $v_{\mathrm{c}}$ and $v_{\mathrm{f}}$ that make the output energy production close to its maximum value. Table 2 shows the results of applying the above mechanism for Al-Razzaza site and the identical turbine speed parameters for that area. Figure- 6 represents the wind frequency (graph bars) and the Weibull distribution (continuous line) over all sectors with a height of 50 meters, plus the values of Weibull statistics; scale parameter, shape parameter, mean wind speed, and wind power density. The normalized rated speed can be obtained corresponds to any point on the normalized power curve. With Weibull scale parameter (c) known for the location, the rated speed of the turbine can be estimated. Other two turbine parameters, namely cut-in and cut-out velocities, are estimated using the relations (17) and (18).

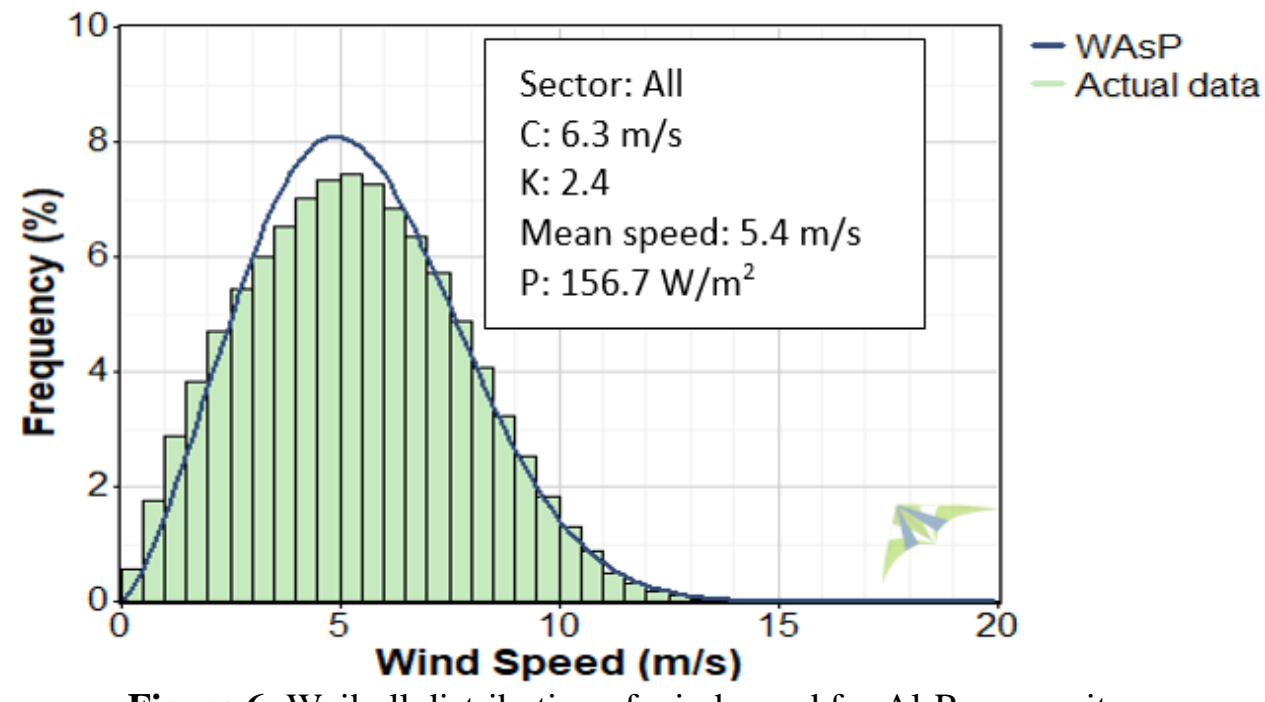

Figure 6- Weibull distribution of wind speed for Al-Razzaza site 
In Figure-7, the normalized power $P_{N}$, capacity factor $C_{f}$ and turbine performance index TPI curves are drawn for a site whose Weibull shape parameter $(\mathrm{k}=2.4)$ and scale parameter $(\mathrm{c}=6.3[\mathrm{~m} / \mathrm{s}])$ are known. The normalized rated speed $\left(v_{\mathrm{r}} / \mathrm{c}\right)$ at $P_{N, \max }$ and $\mathrm{TPI} \mathrm{I}_{\max }$ are obtained from the curve as listed in Table 2. After that, the rated speed of turbine corresponding to $P_{N, \max }$ and $\mathrm{TPI}_{\max }$ can be determined using Weibull scale parameter. The cut-in and cut-out speed parameters of the turbine are computed using the relationships mentioned in Equations (17) and (18).

Table 2- Turbine speed parameter estimation for a site

\begin{tabular}{|c|c|c|}
\hline Parameters & at $\boldsymbol{P}_{N, \text { max }}$ & at $\mathbf{T P I}_{\text {max }}$ \\
\hline $\boldsymbol{v}_{\mathbf{r}} \mathbf{c}$ & 02.08 & 01.18 \\
\hline $\boldsymbol{v}_{\mathbf{r}}$ & 03.50 & 01.99 \\
\hline $\boldsymbol{v}_{\mathbf{c}}$ & 12.72 & 07.22 \\
\hline $\boldsymbol{v}_{\mathbf{f}}$ & 23.53 & 13.36 \\
\hline $\boldsymbol{P}_{\boldsymbol{N}}$ & 01.21 & 00.82 \\
\hline $\boldsymbol{C}_{\boldsymbol{f}}$ & 00.67 & 00.50 \\
\hline
\end{tabular}

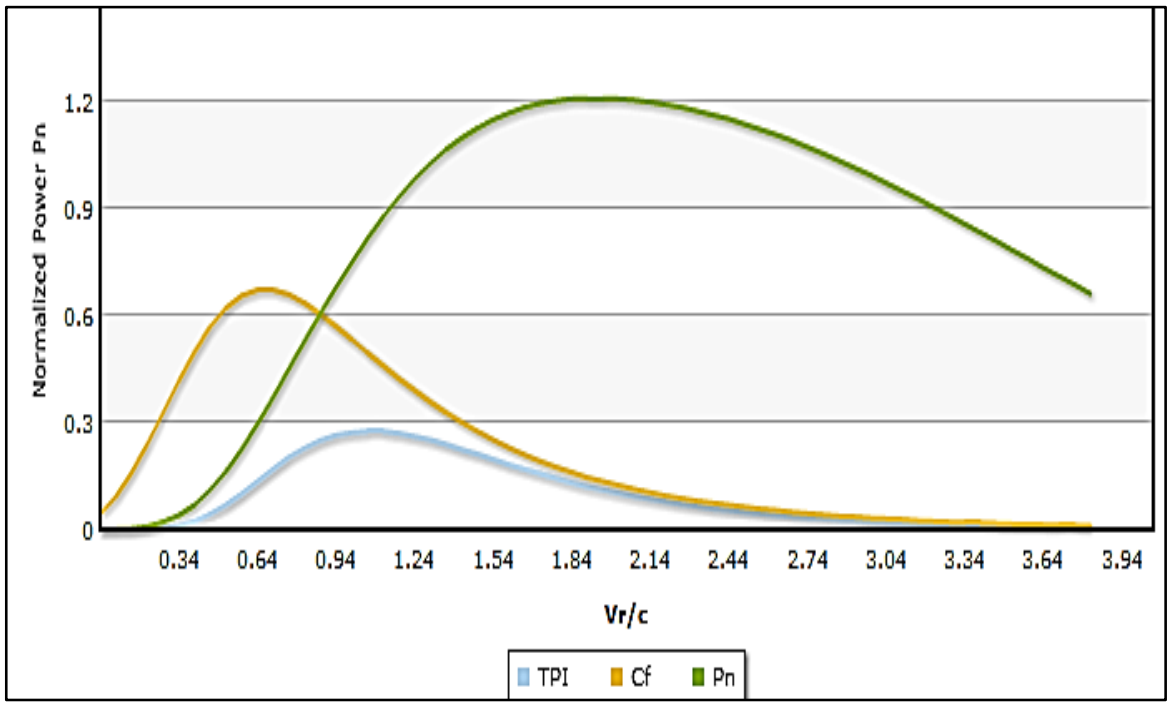

Figure 7- Normalized power, capacity factor and turbine performance index curve for Al-Razzaza site

Table 2 suggests the wind turbine parameters for Al-Razzaza site that give high output power generation. The Weibull scale and shape parameters for Al-Razzaza site are $6.3[\mathrm{~m} / \mathrm{s}]$ and 2.4. The normalized power $P_{N}$, capacity factor $C_{f}$ and turbine performance index TPI curves are shown in Figure7 and the necessary computations are given in Tables 2 and Table 3 . Table 3 is dedicated to identify the best matched wind turbine for Al-Razzaza site from eleven turbines. From Table 3, it is found that the maximum turbine performance index and must suitable turbine from eleven systems are belong to $\mathrm{C} \& \mathrm{~F}$ Green energy 20 [kW], Deimos DT2160 60 [kW] and Electriawind Garbi $150[\mathrm{~kW}]$ wind turbines which they have the same TPI. The decision of which turbine is to be selected for installation will depend upon the load demand, installation costs and reliability aspects.

Table 3- Performance of wind turbines if installed at Al-Razzaza Site $\left(c=6.3[\mathrm{~m} / \mathrm{s}] ; k=2.4 ; P_{N, \max }=1.24 ; C_{f}=0.66\right)$

\begin{tabular}{|c|c|c|c|c|c|c|c|c|c|c|}
\hline \multirow[b]{2}{*}{ No. } & \multirow[b]{2}{*}{ Make } & \multirow[b]{2}{*}{$\begin{array}{l}\text { Rate } \\
\text { Pwr } \\
{[\mathrm{kW}]}\end{array}$} & \multicolumn{3}{|c|}{ Operating Data } & \multirow[b]{2}{*}{$\frac{v_{r}}{c}$} & \multirow[b]{2}{*}{$P_{N}$} & \multirow[b]{2}{*}{$C_{f}$} & \multirow[b]{2}{*}{$\frac{P_{N}}{P_{N, \max }}$} & \multirow[b]{2}{*}{ TPI } \\
\hline & & & $\begin{array}{l}v_{\mathrm{c}} \\
{[\mathrm{m} / \mathrm{s}]}\end{array}$ & $\begin{array}{l}v_{\mathrm{r}} \\
{[\mathrm{m} / \mathrm{s}}\end{array}$ & $\begin{array}{l}v_{\mathrm{f}} \\
{[\mathrm{m} / \mathrm{s}]}\end{array}$ & & & & & \\
\hline 1. & Fortis Monta & 5 & 3 & 21 & 25 & 3.33 & 0.94 & 0.02 & 76.0 & 0.02 \\
\hline 2. & Aircon 10S & 10 & 3.5 & 11 & 25 & 1.74 & 1.20 & 0.22 & 96.5 & 0.17 \\
\hline 3. & C\&FGreen energy & 20 & 1.5 & 9 & 15 & 1.42 & 1.05 & 0.35 & 84.3 & 0.23 \\
\hline
\end{tabular}




\begin{tabular}{|l|l|l|l|l|l|l|l|l|l|l|}
\hline 4. & Endurance G3120 & 35 & 3.5 & 11 & 25 & 1.74 & 1.20 & 0.22 & 96.0 & 0.17 \\
\hline 5. & Orenda Skye & 49 & 4 & 10 & 25 & 1.58 & 1.14 & 0.27 & 91.8 & 0.20 \\
\hline 6. & Deimos DT2160 & 60 & 3 & 9 & 20 & 1.42 & 1.05 & 0.35 & 84.3 & 0.23 \\
\hline 7. & Electriawind G. & 150 & 2.5 & 9 & 25 & 1.42 & 1.05 & 0.35 & 84.3 & 0.23 \\
\hline 8. & Micon & 200 & 4 & 14 & 25 & 2.22 & 0.86 & 0.11 & 69.0 & 0.08 \\
\hline 9. & Endurance X30 & 225 & 4 & 15 & 25 & 2.38 & 1.22 & 0.08 & 98.1 & 0.06 \\
\hline 10. & Enercon E48 & 800 & 3 & 12 & 34 & 1.90 & 1.23 & 0.17 & 99.1 & 0.13 \\
\hline 11. & Vestas V52 & 850 & 4 & 14 & 25 & 2.22 & 0.86 & 0.11 & 69.0 & 0.08 \\
\hline
\end{tabular}

\section{Conclusions}

From the resultant wind rose it is obvious that the appropriate direction for the wind farm is northwest, specifically distributed between sectors 330 and 300. A new method of matching wind turbine generators systems to a site using Turbine performance index, normalized power, and capacity factor curves is presented in this work. The most suitable wind turbine to our chosen site (Al-Razzaza) can be found by calculating optimum wind turbine speed parameters from TPI curve, which is obtained from the normalized curves, so as to yield high output energy production. Maximum peak curve for TPI expressed by normalized rated wind speed can help us to find wind turbine parameters. This peak can be found from plots of normalized power, capacity factor and TPI versus normalized rated wind speed for a known value of Weibull shape parameter of a site. For our case of study, an eleven wind turbines are studied for site matching in order to show the usefulness of this technique in finding optimum wind turbine generator parameters. It is found that C\&F Green energy 20 [kW], Deimos DT2160 60 [kW], and Electriawind Garbi $150[\mathrm{~kW}]$ have highest and same TPI. Also, depending on results, the C\&f will turning and generating electricity for about $90 \%$ of the time, then Deimos $84 \%$ and Electriawind Gabri $90 \%$.Then in order to decide which wind turbine is the best for installation will depends on installation cost, reliability and load demand. From above it can infer that this tool is useful to make a good choice of a wind turbine having ideal speed parameters to give higher output energy.

\section{References}

1. Shamma'a, A., Abdullrahman, A., Addoweesh, K. E., \& Eltamaly, A. 2012. Optimum Wind Turbine Site Matching for Three Locations in Saudi Arabia. In Advanced Materials Research, 347: 2130-2139. Trans Tech Publications Ltd..

2. MERRA data, managed by the NASA Goddard Earth Sciences (GES) Data and Information Services Center (DISC), https://disc.gsfc.nasa.gov.

3. Nemes, C., \& Munteanu, F. 2011. The wind energy system performance overview: capacity factor vs. technical efficiency. International Journal of Mathematical Models and Methods in Applied Sciences, 5(1): 159-166.

4. Global Wind Atlas, https://globalwindatlas.info/en/area/Iraq?print=true

5. Silva G., Pereira A., Faro D., Feitosa E. 2005 "On the Accuracy of the Weibull Parameters Estimators ", Brazilian Wind Energy Centre, Federal University of Pernambuco, Coletânea de Artigos- Energia Solar e Eólica, 2, 2005.

6. Shaban, A. H., Resen, A. K., \& Bassil, N. 2020. Weibull parameters evaluation by different methods for windmills farms. Energy Reports, 6: 188-199.

7. Abdel-Hamid, R. H., Adma, M. A., Fahmy, A. A., \& Samed, S. F. A. 2009. New Technique for Identifying Optimal Generating Units Parametes for Wind Energy Plant. East-West Economic Corridor, Marseille.

8. Teyabeen, A. A., Akkari, F. R., \& Jwaid, A. E. 2017. Power curve modelling for wind turbines. In 2017 UKSim-AMSS 19th International Conference on Computer Modelling \& Simulation (UKSim) (pp. 179-184). IEEE. 